\title{
UTILIZAÇÃO DO CONTROLE ESTATÍSTICO DE PROCESSOS (CEP) COMO INDICADOR DE VIOLAÇÃO EM PROGRAMAS DE PAGAMENTO DO LEITE PELA QUALIDADE
}

\author{
FABIO HENRIQUe TAKAHASHI ${ }^{1}$, LAERTE DAGHER CASSOLI ${ }^{2}$, PAULO FERNANDO MACHADO ${ }^{3}$ \\ ${ }^{1}$ Pós-graduando da Escola Superior de Agricultura Luiz de Queiroz da Universidade de São Paulo, Piracicaba, SP - \\ fab_taka@hotmail.com \\ ${ }^{2}$ Pesquisador Doutor da Escola Superior de Agricultura Luiz de Queiroz da Universidade de São Paulo, Piracicaba, SP. \\ ${ }^{3}$ Professor Doutor da Escola Superior de Agricultura Luiz de Queiroz da Universidade de São Paulo, Piracicaba, SP.
}

\begin{abstract}
Objetivou-se com este estudo utilizar o Controle Estatístico de Processos (CEP) como ferramenta de identificação e classificação de fazendas com maiores probabilidades de violarem o padrão de qualidade utilizado pela indústria. Foram utilizados dados de contagem de células somáticas (CCS) e contagem bacteriana total (CBT) de 452 fazendas. Foram calculadas as proporções de violação nos padrões de qualidade, considerando os limites de CCS $=400.000$ céls. $/ \mathrm{mL}$ e $\mathrm{CBT}=100.000 \mathrm{UFC} / \mathrm{mL}$. Calcularam-se os índices Cpk e classificaram-se as fazendas segundo quatro categorias de médias e de índices Cpk. As fazendas que apresentaram maiores médias e desvios padrão obtiveram maiores
\end{abstract}

frequências de violação. As fazendas com médias inferiores aos limites propostos para CCS e CBT representaram, respectivamente, $25,05 \%$ e $97,78 \%$ das fazendas. Entretanto, a proporção de fazendas que forneceram leite consistentemente dentro dos padrões de qualidade avaliados $(\mathrm{Cpk} \geq 1)$ representou $4,65 \%$ e 35,17 $\%$ das propriedades para CCS e CBT, respectivamente. Portanto, o índice Cpk pode ser utilizado em conjunto com os atuais modelos de caracterização da qualidade do leite de fazendas, uma vez que identifica rebanhos mais consistentes em produzir leite dentro de um padrão de qualidade.

PALAVRAS-CHAVE: bonificação; contagem bacteriana total; contagem de células somáticas; índice Cpk.

\section{APPLICATION OF STATISTICAL PROCESS CONTROL (SPC) AS AN INDEX OF MILK INFRACTION IN QUALITY-BASED PAYMENT SYSTEMS}

\section{ABSTRACT}

The aim of this study was to use the statistical process control (SPC) as a tool of recognition and rating for farms with larger probabilities of infraction of milk quality standards used by industry. Data of somatic cell count (SCC) and total bacterial count (TBC) from 452 farms were used. Proportion of infractions of quality standard was calculated considering limits of SCC $=400,000$ cells $/ \mathrm{mL}$ and $\mathrm{TBC}=100,000 \mathrm{CFU} / \mathrm{mL}$. Indices Cpk were calculated and farms were rated according to four categories of $\mathrm{Cpk}$ means and indices. The farms which presented larger means and standard deviation had larger frequencies of violation. Farms with means lower than limits proposed to SCC and TBC represented, respectively, $25.05 \%$ and $97.78 \%$ of farms. However, proportion of farms that provided milk consistently within the quality standards evaluated $(\mathrm{Cpk} \geq 1)$ represented 4.65 $\%$ and $35.17 \%$ of farms for SCC and TBC, respectively. Therefore, the Cpk index can be used by the industry associated with the current models to characterize milk quality from farms, since it identifies more consistent herds in producing quality-standard milk.

KEYWORDS: bonus; Cpk index; somatic cell count; total bacterial count. 


\section{INTRODUÇÃO}

O leite apresenta características qualitativas importantes para a saúde dos consumidores, as quais influenciam diretamente no rendimento industrial e no tempo de prateleira de derivados lácteos. Os aspectos qualitativos são avaliados segundo a contagem de células somáticas (CCS) e a contagem bacteriana total (CBT) presente no leite. Esses parâmetros são indicadores do status higiênicosanitário da fazenda, além de serem utilizados em programas de pagamento do leite pela qualidade (SCHUKKEN et al., 2003; RODRIGUES \& RUEGG, 2005; BERRY et al., 2006). A CCS e a CBT do leite de fazendas são constantemente monitoradas por indústrias nacionais $\mathrm{e}$ internacionais, para caracterizar e bonificar seus produtores (RIBAS et al., 2004; ROMA JÚNIOR et al., 2009; SOUTO et al., 2009).

A caracterização da CCS e da CBT de fazendas, segundo as recomendações do MAPA (Ministério da Agricultura, Pecuária e Abastecimento), é feita através de uma amostragem mensal do leite do tanque e da média geométrica dos resultados analisados nos últimos três meses (BRASIL, 2002). Algumas indústrias, por outro lado, passaram a coletar de quatro a cinco amostras mensais, calculando médias aritméticas desses resultados. Eventualmente, as indústrias eliminam os resultados extremos obtidos no mês e, assim, caracterizam a qualidade do leite das fazendas (NIZA-RIBEIRO et al., 2004). Entretanto, esses modelos de classificação da qualidade do leite estão sujeitos às variações presentes dentro das fazendas, principalmente naquelas com grandes desvios na qualidade.

A qualidade do leite, entre fazendas, sofre grande variação, principalmente em função do tamanho do rebanho, da época do ano, do ambiente e das práticas de manejo adotadas (ZANELA et al., 2006; LUKAS et al., 2008), o que resulta em uma variação excessiva nos resultados de CCS e CBT. Rebanhos menores estão sujeitos a maiores variações, pois uma vaca com CCS elevada contribui consideravelmente para a elevação da CCS do tanque (LUKAS et al., 2008a). Além disso, a amostragem pode comprometer o sistema de classificação atual, haja vista que a variação amostral é influenciada pela qualidade da amostragem e o número de amostras que, segundo estudos, pode não ser suficiente para caracterizar a qualidade do leite (COLDEBELLA et al., 2002; GOODRIDGE et al., 2004).
Diante da variação existente da qualidade do leite, estudos conduzidos por LUKAS et al. (2008a) identificaram que fazendas com mesma média de CCS, porém com amplitudes de variação diferentes (10 a 150 mil céls. $/ \mathrm{mL}$ ), apresentaram maiores chances de violarem os padrões de qualidade propostos, conforme o acréscimo nos desvios padrão. Portanto, a utilização da média como único parâmetro de classificação da qualidade do leite de fazendas possui algumas desvantagens, pois $\mathrm{o}$ parâmetro não descreve adequadamente a CCS do rebanho ao longo do período avaliado (NIZARIBEIRO et al., 2004). Além desse fato, os atuais modelos de caracterização da qualidade do leite não consideram os efeitos de variação que afetam a CCS e a CBT e não permitem que seja prevista a qualidade do leite nas próximas coletas.

Uma vez que o modelo atual de caracterização da qualidade do leite é uma ferramenta reativa, passível de ser influenciada por grandes variações, há a necessidade de se utilizar métodos matemáticos ou estatísticos que caracterizem possíveis violações no padrão de qualidade. Esses métodos permitiriam à indústria e ao produtor adotarem, juntos, medidas proativas para evitar, ou minimizar, o decréscimo na qualidade do leite na próxima captação. Uma ferramenta para tal procedimento é o controle estatístico de processos (CEP).

O controle estatístico de processos (CEP) é um conjunto de ferramentas de monitoramento, controle e melhoria da qualidade de processos através de análises estatísticas (De VRIES \& RENEAU, 2010). Um processo pode ser compreendido como um sistema (máquina) que transforma "entradas" (insumos) em produtos com características de qualidade. Os rebanhos, portanto, podem ser considerados como processos de produção, com várias entradas (alimentação, genética, infraestrutura e manejo), que serão processadas pela "máquina" (animal), resultando como produto final o leite (NIZA-RIBEIRO et al., 2004). Sob essa perspectiva, é possível aplicar métodos de controle da qualidade em nível de fazendas.

Avaliar o desempenho e o comportamento de processos é o objetivo do CEP, que utiliza o índice de capacidade (Cpk) para medir a consistência dos processos em atender a um padrão de qualidade específico (LUKAS et al., 2005). Portanto, o conceito de Cpk relaciona a média e a variação dos dados do rebanho com um critério específico (limite de 400 mil céls. $/ \mathrm{mL}$ ), fazendo uma relação direta 
entre as informações do rebanho e um padrão de qualidade (NIZA-RIBEIRO et al., 2004).

Um processo com valor de Cpk igual ou superior a 1 é um bom processo, uma vez que respeita consistentemente as especificações de qualidade do produto. Por outro lado, valores de Cpk inferiores a 1, especialmente os negativos, representam processos inadequados (MONTGOMERY, 2004). Porém, dependendo do sistema de controle da qualidade, valores entre 1 e 2 são indicativos de processos consistentes (LUKAS et al., 2008).

O índice de capacidade é um indicador robusto da qualidade do leite, mostrando-se bem acurado para descrever a aptidão do rebanho em relação aos limites legais de CCS (NIZA-RIBEIRO et al., 2004). Além disso, o Cpk é uma ferramenta ideal na gestão dos sistemas produtores de leite, podendo ser usado tanto pela indústria quanto pelos órgãos oficiais de inspeção. Lukas et al. (2008) salientam que o uso do CEP pode auxiliar as indústrias processadoras a identificar rebanhos que têm maior consistência em manter a CCS dentro de um padrão de qualidade ao longo do tempo.

Objetivou-se com este estudo, portanto, utilizar o Controle Estatístico de Processos (CEP) como ferramenta de identificação e classificação de fazendas com maiores probabilidades de violarem o padrão de qualidade utilizado pela indústria. Os objetivos específicos foram: (a) avaliar a proporção de fazendas que violaram o padrão de qualidade em função de suas médias e desvios padrão e (b) estudar o índice de capacidade (Cpk) como método aplicável nos modelos de caracterização da qualidade do leite.

\section{MATERIAL E MÉTODOS}

Foram utilizados dados de 452 fazendas, obtidos do banco de dados da Clínica do Leite ESALQ/ USP, no período de janeiro de 2009 a março de 2010. As informações foram obtidas de fazendas participantes em programas de pagamento do leite pela qualidade, considerando cinco amostragens mensais por fazenda. Todas as fazendas utilizadas no presente estudo são fornecedoras de leite de uma única indústria.

Foram calculadas as médias e os desvios padrão (DP) mensais de CCS e CBT para cada fazenda no estudo. Os maiores valores mensais de CCS e CBT, de cada fazenda, foram registrados e utilizados como indicadores de violação das variáveis utilizadas. Foi considerada uma violação dentro de cada mês se o maior valor da variável no mês seguinte foi maior que o padrão de qualidade estabelecido (CCS > 400 mil céls./mL e CBT > 100 $\mathrm{mil} \mathrm{UFC} / \mathrm{mL}$ ). Foram desenvolvidas quatro faixas de médias para CCS (CCS < 150.000 céls./mL; 150.000 céls. $/ \mathrm{mL} \leq \mathrm{CCS}<250.000$ céls. $/ \mathrm{mL} ; 250.000$ céls. $/ \mathrm{mL} \leq \mathrm{CCS}<350.000$ céls. $/ \mathrm{mL}$ e 350.000 céls. $/ \mathrm{mL} \leq \mathrm{CCS}<400.000$ céls. $/ \mathrm{mL}$ ) e para CBT (CBT $<25.000 \mathrm{UFC} / \mathrm{mL} ; 25.000 \mathrm{UFC} / \mathrm{mL} \leq \mathrm{CBT}<$ $50.000 \mathrm{UFC} / \mathrm{mL} ; 50.000 \mathrm{UFC} / \mathrm{mL} \leq \mathrm{CBT}<75.000$ $\mathrm{UFC} / \mathrm{mL}$ e $75.000 \mathrm{UFC} / \mathrm{mL} \leq \mathrm{CBT}<100.000$ $\mathrm{UFC} / \mathrm{mL}$ ). A partir dessas informações foram descritas as frequências de violação no padrão de qualidade proposto.

Após realizado o teste de normalidade dos dados de CCS e CBT (Shapiro-Wilk), diagnosticouse a não normalidade dos mesmos; em seguida, procedeu-se à transformação dos dados com a finalidade de normalizá-los. Os dados de CCS $\left(10^{3}\right.$ céls. $\left./ \mathrm{mL}\right)$ foram transformados utilizando-se a escala logarítmica para Escore de Células Somáticas (ECS), em que ECS $=\log _{2}(\mathrm{CCS} / 100)+3$, de acordo com metodologia adotada por ANDRADE et al. (2007). Já para os dados de CBT $\left(10^{3} \mathrm{UFC} / \mathrm{mL}\right)$, a transformação utilizada foi a tCBT $=\log _{10}$ $(\mathrm{CBT}+0,5)$ conforme descrito por BRITO et al. (2000). Para proceder à análise de dados em controle estatístico de processos, é necessário que os dados estejam normalmente distribuídos (MONTGOMERY, 2004). Portanto, as análises envolvendo o CEP e suas comparações foram efetuadas com os valores transformados.

Os dados de ECS e tCBT das 452 fazendas foram utilizados para o desenvolvimento dos cálculos de capacidade considerando todo o período. Os índices de capacidade (Cpk) para cada variável foram calculados para cada fazenda, de acordo com o limite superior de especificação (LSE) de $400 \mathrm{mil}$ céls./mL para CCS $(E C S=5)$ e $100 \mathrm{mil} \mathrm{UFC} / \mathrm{mL}$ para $\mathrm{CBT}(\mathrm{tCBT}=5)$.

O modelo para o cálculo de $\mathrm{Cpk}$ foi o de $\mathrm{Cpk}$ $=(\mathrm{LSE}-\overline{\mathrm{y}}) /\left[2,782 \times\left(\mathrm{MR} / \mathrm{d}_{2}\right)\right]$, em que y é a média da variável de interesse no período, MR é a média da amplitude móvel da variável e $\mathrm{d}_{2}$ é um valor tabulado de acordo com o número de amostras. Para o presente estudo, utilizou-se a amplitude móvel (MR) de duas observações consecutivas, sendo $\mathrm{d}_{2}=1,128$. A amplitude móvel foi obtida pela expressão: $\mathrm{MR}_{\mathrm{i}}=\left|\mathrm{x}_{\mathrm{i}}-\mathrm{X}_{\mathrm{i}-1}\right| . \mathrm{O}$ modelo do Cpk utilizado foi adaptado para o presente estudo, que considera as análises de capacidade de CCS e CBT como processos unilaterais.

MONTGOMERY (2004) descreve o modelo de $\mathrm{Cpk}$ como $\mathrm{Cpk}=(\mathrm{LSE}-\overline{\mathrm{y}}) /\left[\mathrm{C} 3 \mathrm{x}\left(\mathrm{MR} / \mathrm{d}_{2}\right)\right]$; entretanto, esse modelo é válido para processos bilaterais que apresentam uma probabilidade de 0,27\% para que um valor esteja fora dos limites de controle (MONTGOMERY, 2004). Para que o processo unilateral, no presente estudo, mantivesse a mesma probabilidade de $0,27 \%$, o número de desvios 
necessários foi representado por 2,782. Os processos unilaterais são aqueles cujo interesse do monitoramento situa-se apenas em uma das faixas de controle (acima ou abaixo da média), conforme relatado por GONÇALEZ e WERNER (2009). As análises de capacidade foram desenvolvidas utilizando-se o software Minitab 16.

As fazendas foram classificadas segundo quatro categorias (A, B, C e D), de médias de CCS ( $\overline{\mathrm{X}} \mathrm{CCS}$ A: $\mathrm{CCS}<4,0 \times 10^{5}$ céls. $/ \mathrm{mL} ; \overline{\mathrm{X}} \mathrm{CCS}$ B: $4,0 \times 10^{5} \leq \mathrm{CCS}<7,5 \times 10^{5}$ céls. $/ \mathrm{mL} ; \overline{\mathrm{X}} \mathrm{CCS} \mathrm{C}$ : $7,5 \times 10^{5} \leq \mathrm{CCS}<1,0 \times 10^{6}$ céls. $/ \mathrm{mL} ; \overline{\mathrm{XCCS}} \mathrm{D}: \mathrm{CCS} \geq$ $1,0 \times 10^{6}$ céls. $\left./ \mathrm{mL}\right)$. Quanto à $\mathrm{CBT}$, as categorias de médias foram de $\overline{\mathrm{X}} \mathrm{CBT}$ A: CBT $<1,0 \times 10^{5} \mathrm{UFC} / \mathrm{mL}$; $\overline{\mathrm{X}} \mathrm{CBT} \mathrm{B}: 1,0 \times 10^{5} \leq \mathrm{CBT}<7,5 \times 10^{5} \mathrm{UFC} / \mathrm{mL} ; \overline{\mathrm{X}} \mathrm{CBT}$ C: $7,5 \times 10^{5} \leq \mathrm{CBT}<1,0 \times 10^{6} \mathrm{UFC} / \mathrm{mL}$ e $\overline{\mathrm{XCBT}} \mathrm{D}$ : $\mathrm{CBT} \geq 1,0 \times 10^{6} \mathrm{UFC} / \mathrm{mL}$. Para os índices de capacidade, as classes foram de $\mathrm{Cpk} \mathrm{A}$ : $\mathrm{Cpk} \geq 2$; Cpk B: $1 \leq \mathrm{Cpk}<2$; Cpk C: $0 \leq \mathrm{Cpk}<1$ e Cpk D: Cpk $<0$. Os parâmetros definidos para a presente classificação foram escolhidos segundo as metas parciais descritas na IN 51 (BRASIL, 2002), considerando que os dados foram obtidos quando os limites máximos para CCS e CBT eram de 750.000 céls. $/ \mathrm{mL}$ e $750.000 \mathrm{UFC} / \mathrm{mL}$, respectivamente. Foram utilizados dados de oito fazendas dentro de cada classe de Cpk (A, B, C e D) para ilustrar a distribuição de ECS e tCBT em cada categoria, através de histogramas de capacidade.

\section{RESULTADOS E DISCUSSÃO}

As frequências de violação, nos padrões de qualidade utilizados, são maiores para fazendas com médias próximas aos limites avaliados (Tabela 1). As maiores médias seguidas de maiores variações resultaram em maiores chances de violação no padrão de CCS. Semelhante resultado para contagem de células somáticas foi observado por LUKAS et al. (2008a), que utilizaram cinco padrões de CCS nos rebanhos avaliados. Os autores verificaram que a frequência de violações foi crescente para as fazendas com maiores médias e sigmas (estimativa do desvio padrão).

Tabela 1 - Frequência de violação de CCS acima de 400 mil cels./ mL de acordo com as faixas de média e desvios padrão

\begin{tabular}{ccccc}
\hline & \multicolumn{4}{c}{ Médias } \\
Desvio padrão* & $<150$ & $150-250$ & $250-350$ & $350-400$ \\
\hline \multirow{2}{*}{$60-75$} & $\ldots$ & $13^{* *}$ & 11 & $\ldots$ \\
& & $(4)^{\dagger}$ & $(5)$ & 59 \\
$75-100$ & $\ldots$ & 14 & 40 & $(6)$ \\
& & $(6)$ & $(9)$ & 61 \\
$100-175$ & $\ldots$ & 26 & 45 & $(21)$ \\
\hline
\end{tabular}

*(x 1000 células/ mL); **Frequência de violações no padrão de CCS (\%); †Número de fazendas na categoria entre parênteses; ... Dados inexistentes nas faixas propostas.

Não foram observadas frequências de violação para contagem bacteriana total dentro dos intervalos avaliados no presente estudo. O banco de dados utilizado no estudo representou informações de uma única indústria, que não dispunha de informações suficientes para determinar violações de CBT dentro das faixas estudadas.

O monitoramento da média e da variação de CCS tem o potencial de alertar tanto produtores quanto indústrias sobre uma futura violação no padrão de qualidade utilizado em programas de pagamento do leite pela qualidade. Portanto, a utilização de um índice que relacione as informações do rebanho (média e variação) com as informações específicas de qualidade permite identificar fazendas com maiores e menores chances de violarem o padrão de qualidade das indústrias.

As comparações entre os resultados de médias e de índices de capacidade (Cpk) das variáveis analisadas são apresentadas na Tabela 2. As fazendas classificadas pelas médias e pelos índices Cpk apresentaram distribuições diferentes, independente da variável analisada. Semelhante observação foi descrita por NIZA-RIBEIRO et al. (2004) que, ao estudarem o índice de capacidade como medida da conformidade de rebanhos leiteiros, verificaram que a distribuição das médias e do índice Cpk de CCS descreveram diferentes padrões de células somáticas do tanque. 
Tabela 2 - Análise descritiva das médias e dos índices Cpk de ECS e tCBT

\begin{tabular}{ccccccccc}
\hline Variável & Média & DP & N & Q1 & Med. & Q3 & Mín. & Max. \\
\hline Cpk ECS & $-0,66$ & 1,05 & 451 & $-1,21$ & $-0,63$ & 0,004 & $-5,35$ & 2,65 \\
Média ECS & 5,41 & 0,70 & 451 & 4,99 & 5,47 & 5,87 & 2,98 & 7,34 \\
Cpk tCBT & 0,79 & 0,59 & 452 & 0,33 & 0,74 & 1,17 & $-0,54$ & 2,94 \\
Média tCBT & 4,44 & 0,34 & 452 & 4,18 & 4,41 & 4,69 & 3,73 & 5,51
\end{tabular}

DP: Desvio Padrão; N: Número de amostras; Q1: Primeiro quartil; Med.: Mediana; Q3: Terceiro quartil; Mín.: Mínimo; Max.: Máximo.

Observou-se que os parâmetros de tendência central (média e mediana) das médias de escore de células somáticas (ECS) das fazendas classificadas estão acima do limite de especificação proposto (LSE de ECS = 5), da mesma forma, verificou-se que a média e a mediana do índice de capacidade de ECS (Cpk-ECS) estão abaixo de 1, representando processos incapazes de atender à especificação (Tabela 2). Entretanto, os parâmetros de tendência central das médias de contagem bacteriana total transformada (tCBT) estão dentro da especificação (LSE de tCBT $=5$ ), embora com índices de capacidade inferiores a 1 , também representando processos incapazes (Tabela 2).

Do total de fazendas avaliadas quanto ao ECS, 25,05\% apresentaram média de ECS inferior a 5 (Tabela 3). Contudo, as fazendas capazes de fornecer leite dentro dos padrões estabelecidos no estudo ( $\mathrm{Cpk} \geq 1$, classes A e B de Cpk-ECS) representaram 4,65\% das fazendas (Tabela 3). Portanto, 95,35 \% das fazendas avaliadas quanto a células somáticas não foram capazes de manter, consistentemente, o padrão de qualidade sugerido (400 mil céls./ mL). Esse padrão será exigido pela IN 51 (BRASIL, 2002) a partir de Julho de 2011 nas regiões Sul, Sudeste e Centro Oeste

Tabela 3 - Classificação das fazendas para ECS em todo o período

\begin{tabular}{|c|c|c|c|c|c|}
\hline \multirow{2}{*}{ Classe de Cpk* } & \multicolumn{4}{|c|}{ Classe de média** } & \multirow{2}{*}{ Totais (linhas) } \\
\hline & $\mathrm{A}$ & $\mathrm{B}$ & $\mathrm{C}$ & $\mathrm{D}$ & \\
\hline A & 2 & 0 & 0 & 0 & 2 \\
\hline B & 19 & 0 & 0 & 0 & 19 \\
\hline $\mathrm{C}$ & 92 & 0 & 0 & 0 & 92 \\
\hline $\mathrm{D}$ & 0 & 238 & 62 & 38 & 338 \\
\hline Totais (colunas) & 113 & 238 & 62 & 38 & 451 \\
\hline
\end{tabular}

Quando analisada a classificação em função da contagem bacteriana, verificou-se que 422 fazendas foram capazes de atender a especificação proposta, quando se utilizou a média de tCBT como parâmetro de classificação (Tabela 4). Entretanto, quando se utilizou o Cpk como indicador, verificouse que 159 fazendas foram classificadas como capazes de atender ao parâmetro de qualidade $(\mathrm{Cpk} \geq$ 1, classes A e B de Cpk-tCBT). 
Tabela 4 - Classificação das fazendas para tCBT em todo o período

\begin{tabular}{cccccc}
\hline \multirow{2}{*}{ Classe de Cpk* Classe de média** } & \multirow{2}{*}{ Totais (linhas) } \\
\cline { 2 - 5 } & $\mathrm{A}$ & $\mathrm{B}$ & $\mathrm{C}$ & $\mathrm{D}$ & 16 \\
$\mathrm{~A}$ & 16 & 0 & 0 & 0 & 143 \\
B & 143 & 0 & 0 & 0 & 263 \\
C & 263 & 0 & 0 & 0 & 30 \\
D & 0 & 30 & 0 & 0 & 452 \\
\hline Totais (colunas) & 422 & 30 & 0 & 0 & \\
\hline
\end{tabular}

*Classe de Cpk - A: Cpk $\geq 2,0 ;$ B: $1 \leq \mathrm{Cpk}<2$; C: $0 \leq \mathrm{Cpk}<1$; D: Cpk $<0$. ${ }^{* *}$ Classe de média - A: média tCBT $<5$; B: $5 \leq$ média tCBT $<5,87 ; \mathrm{C}: 5,87 \leq$ média tCBT $<6$; $\mathrm{D}:$ média tCBT $\geq 6$.

Do conjunto de fazendas com médias de ECS e tCBT inferiores a 5 (400 mil céls./ $\mathrm{mL}$ e 100 mil UFC/ $\mathrm{mL}$, respectivamente), 21 fazendas apresentaram Cpk-ECS $\geq 1$, enquanto que 159 fazendas obtiveram Cpk-tCBT $\geq 1$ (Tabelas 3 e 4). Portanto, se as fazendas do estudo fossem caracterizadas em função da média por uma indústria que valoriza aquelas com médias de CCS e CBT inferiores aos parâmetros propostos, a indústria estaria bonificando $20,40 \%$ e $58,18 \%$ de fazendas que apresentaram inconsistências nos padrões de CCS e CBT, respectivamente (fazendas na classe C de Cpk). Em outras palavras, fazendas que em algum momento violaram o padrão de qualidade proposto.

As fazendas classificadas como classe $\mathrm{C}$ de Cpk-ECS e Cpk-tCBT apresentaram médias e (desvios padrão) de 4,60 (0,63) e 4,56 (0,51), respectivamente. Entretanto, as propriedades classificadas em A e B de Cpk-ECS e Cpk-tCBT obtiveram médias e desvios padrão inferiores aos observadas na classe C (Tabela 5). As médias e desvios maiores favoreceram a redução dos índices Cpk, pois fazendas com maior variabilidade e média possuem maiores chances de violarem um padrão de qualidade. NIZA-RIBEIRO et al. (2004) relataram que com o aumento da média e da amplitude de células somáticas, menor foi o índice de capacidade (Cpk) observado. Portanto, uma menor média, a não ser que seja acompanhada de uma menor variação, pode fornecer uma falsa impressão da capacidade de um rebanho em atender um determinado padrão de qualidade (LUKAS et al., 2008a).

Tabela 5 - Médias (desvios padrão) de ECS e tCBT das fazendas em cada classe de Cpk

\begin{tabular}{ccccc}
\hline \multirow{2}{*}{ Variáveis } & \multicolumn{5}{c}{ Classe Cpk } \\
\cline { 2 - 5 } & $\mathrm{A}$ & $\mathrm{B}$ & $\mathrm{C}$ & $\mathrm{D}$ \\
\hline ECS & $3,13(0,57)$ & $3,94(0,57)$ & $4,60(0,63)$ & $5,72(0,52)$ \\
tCBT & $4,01(0,24)$ & $4,12(0,36)$ & $4,56(0,51)$ & $5,14(0,56)$ \\
\hline
\end{tabular}

Menores índices de capacidade $(\mathrm{Cpk}<1)$, principalmente os negativos, estão relacionados às maiores prevalências de mastite subclínica (NIZARIBEIRO et al., 2004). Em pesquisa realizada por LUKAS et al. (2004), o Cpk foi correlacionado negativamente com a mastite subclínica dos rebanhos. Nesses estudos foi verificado que rebanhos capazes de atender as especificações testadas $(\mathrm{Cpk} \geq 1)$ representaram $26 \%, 30 \%, 34 \%$ e $38 \%$ dos rebanhos, respectivamente, para os limites de 400 mil, 500 mil, 600 mil e 750 mil céls/ mL. Esses rebanhos representaram uma pequena parcela que forneceu leite consistentemente dentro dos padrões avaliados. Portanto, os menores índices Cpk estão diretamente relacionados a processos ineficientes em atender as especificações.

Observou-se que a dispersão de ECS e de tCBT para cada classe de Cpk apresentou um padrão diferente em relação ao limite superior de especificação (LSE) igual a 5. Os histogramas de capacidade de oito fazendas classificadas dentro de cada categoria de Cpk-ECS e Cpk-tCBT são apresentados nas Figuras 1 e 2, respectivamente. Observou-se que as maiores médias contribuíram com os menores índices Cpk. A maior variabilidade existente nas fazendas com índices Cpk menores do que um indica a necessidade de ações que melhorem a qualidade do leite produzido, como o treinamento de funcionários e a padronização de métodos na ordenha. 


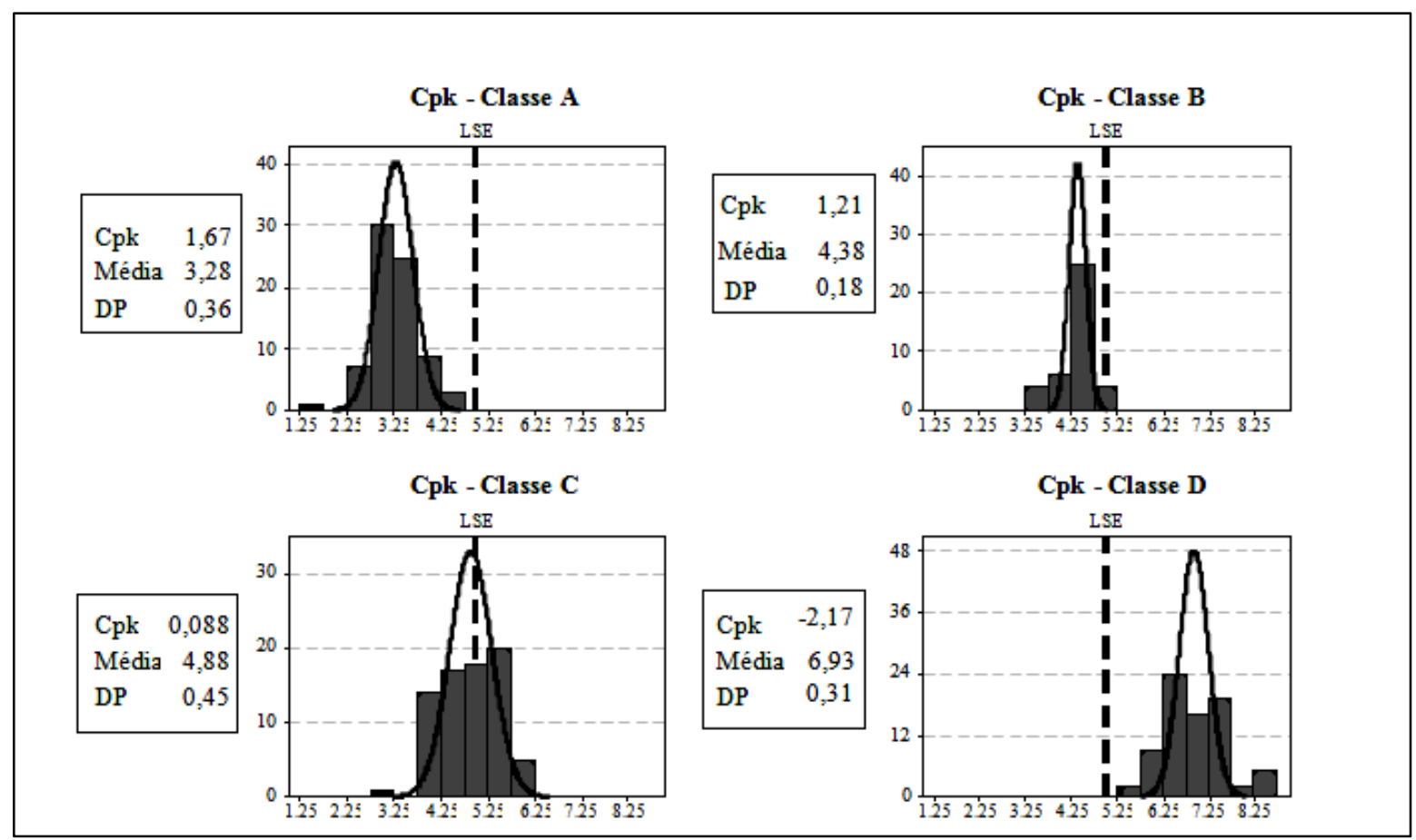

Figura 1 - Histograma de capacidade de ECS para as quatro classificações de Cpk-ECS (A, B, C e D).

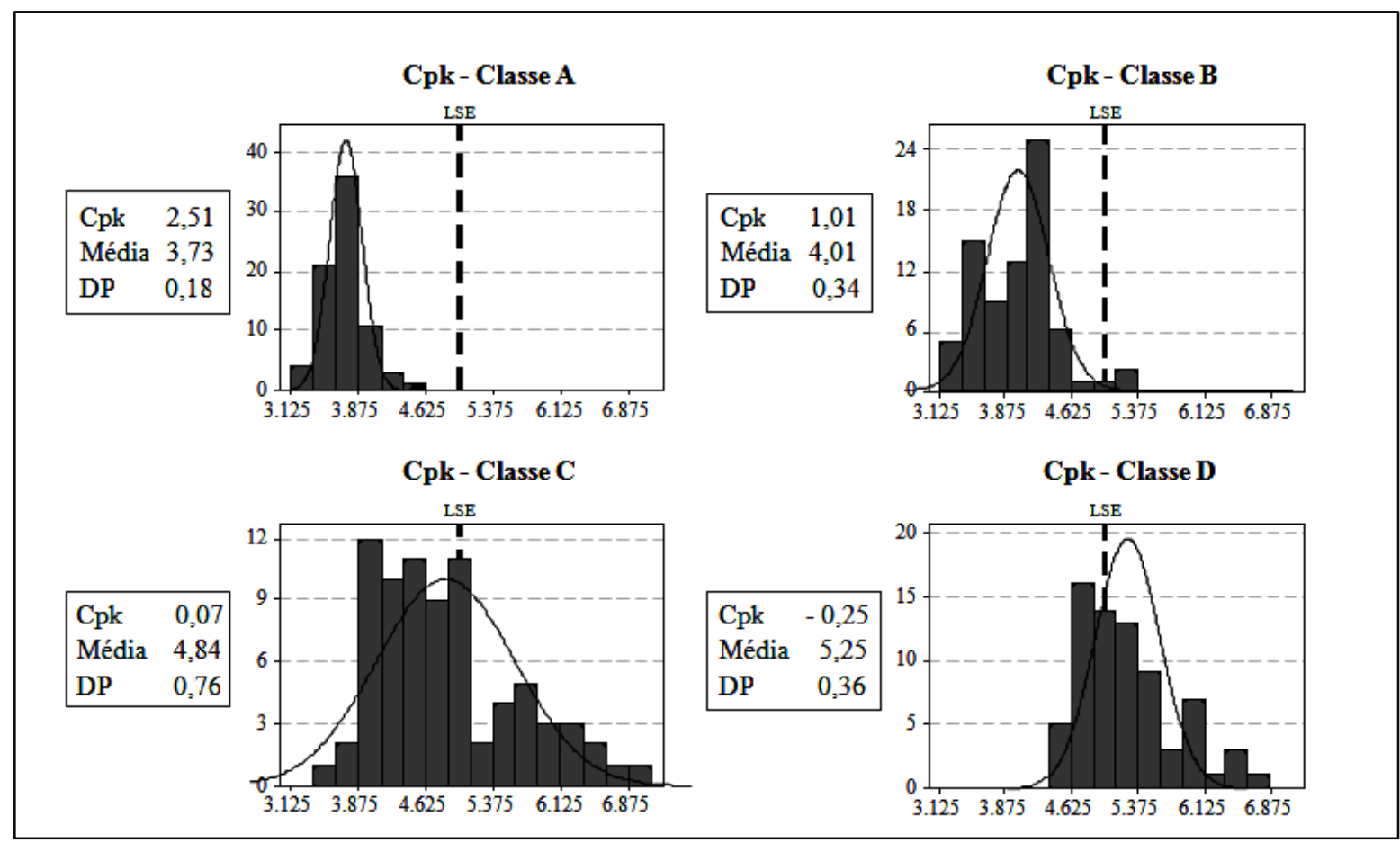

Figura 2 - Histograma de capacidade de tCBT para as quatro classificações de Cpk-tCBT (A, B, C e D).

$\mathrm{O}$ índice $\mathrm{Cpk}$ utiliza as informações estatísticas dos dados, assim como as especificações das indústrias, para identificar processos capazes de Ci. Anim. Bras., Goiânia, v.12, n.4, p. 661 - 669, out./dez. 2011 atender a um padrão de qualidade (NIZA-RIBEIRO et al., 2004). Portanto, o índice de capacidade é uma ferramenta mais precisa em relação à média das 
informações, isoladamente, para identificar fazendas consistentes em atender um padrão de qualidade. No presente estudo, verificou-se que o número de fazendas com potencial para produzir leite com qualidade é reduzido, quando comparado com as fazendas classificadas por NIZA-RIBEIRO et al. (2004) que utilizaram o mesmo LSE e encontraram $20,2 \%$ de fazendas capazes de produzir leite com CCS inferior a 400.000 céls./ mL.

Observa-se que, no grupo de fazendas avaliadas, a capacidade de atender os padrões previstos pela IN 51 para julho de 2011 é mais consistente quando se observa a contagem bacteriana. Um número maior de fazendas foi capaz de atender os padrões de CBT em relação aos de CCS. Provavelmente, a dificuldade de controlar a mastite nos rebanhos leiteiros nacionais seja uma das fontes de variação que mais contribuiu para aumentar as chances de violação nos padrões de qualidade.

Os atuais métodos de caracterização da qualidade do leite podem ser complementados pelo índice Cpk para monitorar e avaliar a qualidade do leite das fazendas, uma vez que o índice de capacidade é um indicador robusto da qualidade do leite produzido (NIZA-RIBEIRO et al., 2004). Lukas et al. (2008) salientaram que o Cpk é uma ferramenta com potencial para utilização em programas de valorização do leite pela qualidade. A adoção do Cpk pelas indústrias pode auxiliar na orientação de produtores a adotarem programas de prevenção e controle da mastite (NIZA-RIBEIRO et al., 2004), considerando que o índice é uma ferramenta passível de ser utilizada na análise de perigos e pontos críticos de controle.

\section{CONCLUSÕES}

As ferramentas empregadas pelo controle estatístico de processos, como o índice $\mathrm{Cpk}$, permitem que violações nos padrões de qualidade sejam detectadas previamente. Essas ferramentas podem ser empregadas em conjunto com os atuais métodos de caracterização da qualidade do leite produzido nas fazendas. Portanto, sua aplicação permite que indústrias e produtores atuem juntos na prevenção de perdas no pagamento do leite e no rendimento industrial.

\section{AGRADECIMENTOS}

À Fundação de Amparo e Pesquisa do Estado de São Paulo (FAPESP) pelo apoio financeiro por meio do processo $n^{\circ}$. 2009/02977 (Mestrado).

\section{REFERÊNCIAS}

ANDRADE, L. M.; FARO, L. E.; CARDOSO, V. L.; ALBUQUERQUE, L. G. A.; CASSOLI, L.D.; . Efeitos genéticos e de ambiente sobre a produção de leite e a contagem de células somáticas em vacas holandesas. Revista Brasileira de Zootecnia, v. 32, n. 2, p. 343-349, 2007.

BERRY, D. P.; O'BRIEN, B.; O'CALLAGHAN, K. O.; SULLIVAN, K. O.; MEANEY, W. J. Temporal trends in bulk tank somatic cell count and total bacterial count in Irish dairy herds during the past decade. Journal of Dairy Science, v. 89, n. 10, p. 4083-4093, 2006.

BRASIL. Instrução Normativa $n^{\circ} 51$, de 18 de setembro de 2002. Estabelece o regulamento fixar os requisitos mínimos que devem ser observados para a produção, a identidade e a qualidade do leite. Diário Oficial da República Federativa do Brasil, Brasília, Seção 1, p.13-22, set. 2002.

BRITO, J. R. F.; BRITO, M. A. V. P.; VERNEQUE, R. S. Contagem bacteriana da superfície de tetas de vacas submetidas a diferentes processos de higienização, incluindo a ordenha manual com participação do bezerro para estimular a descida do leite. Ciência Rural, v. 30, n. 5, p. 847-850, 2000.

COLDEBELlA, A.; MEYER, P. M.; CORASSIN, C. H.; MACHADO, P. F.; CASSOLI, L. D. Determinação do número mínimo de amostragens mensais de leite, para pagamento por qualidade. Higiene Alimentar, v. 16, n. 97, p. 51-55, 2002.

DE VRIES, A.; RENEAU, J. K. Application of statistical process control charts to monitor changes in animal production systems. Journal of Animal Science, v. 88, suppl., p. 11-24, 2010.

GONÇALEZ, P. U.; WERNER, L. Comparação dos índices de capacidade do processo para distribuições nãonormais. Gestão da Produção, v. 16, n. 1, p. 121-132, 2009.

GOODRIDGE, L.; HILL, A. R.; LENCKI, R. W. A review of international standards and the scientific literature on farm milk bulk-tank sampling protocols. Journal of Dairy Science, v. 87, n. 9, p. 3099 - 3104, 2004.

LUKAS, J. M.; HAWKINS, D. M.; KINSEL, M. L.; RENEAU, J. K. Bulk tank somatic cell counts analyzed by statistical process control tools to identify and monitor subclinical mastitis incidence. Journal of Dairy Science, v. 88, n. 11, p. 3944-3952, 2005.

LUKAS, J.; KINSEL, M. L.; RENEAU, J. K. The use of statistical process control capability indices to estimate subclinical mastitis prevalence and new infection rates. Journal of Dairy Science, v. 87, suppl., p. 140, 2004.

LUKAS, J. M.; RENEAU, J.; KINSEL, M. L. Predicting somatic cell count standard violations based on herd's 
bulk tank somatic cell count. Part I: Analyzing variation. Journal of Dairy Science, v. 91, n. 1, p. 427-432, 2008a.

LUKAS, J. M.; RENEAU, J.; MUNOZ-ZANZI, C.; KINSEL, M. L. Predicting somatic cell count standard violations based on herd's bulk tank somatic cell count. Part II: Consistency Index. Journal of Dairy Science, v. 91, n. 1, p. 433-441, 2008.

MONTGOMERY, D. C. Introdução ao controle estatístico da qualidade. $4^{\text {nd }}$ ed. Rio de Janeiro, RJ: Livros técnicos e científicos, 2004.

NIZA-RIBEIRO, J.; NOORDHUIZEN, J. P. T. M.; MENEZES, J. C. Capability index - A statistical process control tool to aid in udder health control in dairy herds. Journal of Dairy Science, v. 87, n. 8, p. 2459-2467, 2004.

RIBAS, N. P.; HARTMANN, W.; MONARDES, H. G.; ANDRADE, U. V. C. Sólidos totais do leite em amostras de tanque nos estados do Paraná, Santa Catarina e São Paulo. Revista Brasileira de Zootecnia, v. 33, n. 6, p. 2343 - 2350, 2004.

RODRIGUES, A. C. O.; RUEGG, P. L. Management of Wisconsin dairy herds enrolled in milk quality teams.
Journal of Dairy Science, v. 88, n. 7, p. 2660-2671, 2005.

ROMA JÚNIOR, L. C.; MONTOYA, J. F. G.; MARTINS, T. T.; CASSOLI, L. D.; MACHADO, P. F. Sazonalidade do teor de proteína e outros componentes do leite e sua relação com o programa de pagamento por qualidade. Arquivo Brasileiro de Medicina Veterinária e Zootecnia, v. 61, n. 6, p. 1411-1418, 2009.

SCHUKKEN, Y. H.; WILSON, D. J.; WELCOME, F.; GARRISON-TIKOFSKY， L.; GONZALEZ， R. N. Monitoring udder health and milk quality using somatic cell counts. Veterinary Research, v. 34, n. 5, p. 579-596, 2003.

SOUTO, L. I. M.; SAKATA, S. T.; MINAGAWA, C. Y.; TELLES, E. O.; GARBUGLIO, M. A.; BENITES, N. R. Qualidade higiênico-sanitária do leite cru produzido em propriedades do estado de São Paulo, Brasil. Veterinária e Zootecnia, v. 16, n. 3, p. 491-499, 2009.

ZANELA, M. B.; FISCHER, V.; RIBEIRO, M. E. R.; JUNIOR, W. S.; ZANELA, C.; MARQUES, L. T.; MARTINS, P. R. G. Qualidade do leite em sistemas de produção na região sul do Rio Grande do Sul. Pesquisa Agropecuária Brasileira, v. 41, n. 1, p. 153-159, 2006. 